\title{
Cross-cultural adaptation and validation of the Polish version of the Core Outcome Measures Index for low back pain
}

\author{
Grzegorz Miekisiak • Marta Kollataj • Jan Dobrogowski • Wojciech Kloc • \\ Witold Libionka - Mariusz Banach · Dariusz Latka - Tomasz Sobolewski • \\ Adam Sulewski · Andrzej Nowakowski · Grzegorz Kiwic · Adam Pala • \\ Tomasz Potaczek
}

Received: 7 August 2012/Revised: 3 November 2012/Accepted: 24 November 2012/Published online: 12 December 2012

(c) Springer-Verlag Berlin Heidelberg 2012

\begin{abstract}
Purpose The Core Outcome Measures Index (COMI) is a short, multidimensional outcome scale validated for the use by patients with spinal disorders. It is a recommended instrument in the Spine Society of Europe Spine Tango Registry. The purpose of this study was to produce a crossculturally adapted and validated Polish COMI.

Methods The cross-cultural adaptation was carried out using the established guidelines. One-hundred and sixtynine patients with chronic low back pain were enrolled, 89 took part in the reproducibility part of the study.
\end{abstract}

Electronic supplementary material The online version of this article (doi:10.1007/s00586-012-2607-2) contains supplementary material, which is available to authorized users.

G. Miekisiak ( $\square)$

Department of Neurosurgery, Specialist Medical Center,

ul. Jana Pawla II 2, 57-320 Polanica-Zdroj, Poland

e-mail: gmiekisiak@gmail.com

M. Kollataj · J. Dobrogowski

Department of Pain Research and Treatment, Jagiellonian

University, Cracow, Poland

W. Kloc

Department of Neurology and Neurosurgery, Faculty of Medical

Sciences, University of Varmia and Masuria, Olsztyn, Poland

W. Libionka

Department of Neurosurgery, Pomeranian Traumatology Center,

Gdansk, Poland

M. Banach

Department of Neurosurgery, Sokolowski Hospital,

Wałbrzych, Poland

D. Latka $\cdot$ T. Sobolewski

Department of Neurosurgery, Regional Medical Center,

Opole, Poland
Data quality, construct validity and reproducibility were assessed.

Results The quality of data was very good with very few missing answers and modest floor effect. Reliability expressed as intraclass correlation coefficient (ICC) was 0.90 (95\% CI 0.85-0.93) for the overall COMI score and for most of the individual core items. The minimum detectable change $\left(\mathrm{MDC}_{95 \%}\right)$ was 1.79 .

Conclusions The Polish version of COMI showed a favorable reproducibility similar to that of previously tested language versions. The COMI scores correlated sufficiently with existing measures. This version of the COMI is a valuable instrument for the use by Polishspeaking patients with spinal disorders.

\section{A. Sulewski · A. Nowakowski}

Department of Spinal Surgery, University of Medical Sciences, Poznan, Poland

G. Kiwic

Department of Neurosurgery, Regional Specialist Hospital,

Jastrzebie-Zdroj, Poland

A. Pala

Spine Department, District Orthopaedic Hospital,

Piekary Slaskie, Poland

T. Potaczek

Department of Orthopaedics and Rehabilitation,

Jagiellonian University, Zakopane, Poland 
Keywords COMI - Validation · Questionnaire ·

Low back pain

\section{Introduction}

In the field of spine research, objective evaluation of symptoms of patients with low back pain (LBP) is a challenging task. An objective assessment is of critical importance for the monitoring of outcomes of various treatment methods. Over the last two decades, patientrelated outcome measurements have become the mainstay of treatment outcome monitoring for use in patients with musculoskeletal disorders, such as LBP [1]. Numerous disability scales have been proposed to date, such as Oswestry Disability Index [2], Roland-Morris Disability Questionnaire [3], Quebec Back Pain Disability Scale [4] and others. They all evaluate the influence of LBP on several domains of living. None of them is perfect since they are all a compromise between survey length and precision-a greater number of more complex questions may increase the number of unanswered questions but on the other hand when it is very short and simple, the accuracy may be hampered.

In 1998 Deyo et al. [5] recommended a novel set of seven core questions as a reliable instrument for the assessment of outcomes in LBP. It was further developed into the Core Outcome Measures Index (COMI). COMI is a relatively short self-administered multidimensional questionnaire intended to assess the influence of LBP on several domains of everyday life. The psychometric properties of COMI have been assessed by several independent research groups [6-10], proving it to be a valid and highly responsive instrument. It has been adapted and validated for the use in German [8, 11], Spanish [7], French [12], Italian [1], Brazilian-Portuguese [13] and Norwegian [14] versions. Analogous version of COMI for patients with neck pain and related disorders was developed, adapted and validated for use in German [15] and English [9] versions. Good reliability and responsiveness of COMI combined with its brevity and multilingual availability make it an attractive instrument for use in large multicenter international studies. It has been selected as the questionnaire of choice in the Spine Society of Europe's "Spine Tango" Registry of surgical and conservative treatment of spinal disorders.

The aims of this study were to deliver a culturally adapted validated version of COMI for the use in Polishspeaking patients and to enable Polish medical professionals dealing with spinal disorders to participate in the "Spine Tango" Registry.

\section{Methods}

\section{The COMI}

The COMI is a self-administered questionnaire comprised of seven items intended to evaluate the intensity of the leg and back pain, difficulties in everyday life, symptom-specific well-being, the social and work disability and general quality of life. It has been described in details by Mannion et al. [11]. In short, the overall COMI score is computed by adding the highest score of the adjusted leg/back pain subset to the sum of remaining subscales and divided by 5 , so it ranges from 0 (best health status) to 10 (worst health status).

Translation and cross-cultural adaptation

The translation and cross-cultural adaptation of the original English version of the COMI into Polish was carried out in accordance with recommendations of the American Academy of Orthopedic Surgeons (AAOS) as described in detail by Beaton et al. [16]. The study was approved by the Ethics Committee.

Translation and synthesis

Two bilingual translators whose first language was Polish independently translated the original English version of COMI obtained from the official website of Spine Tango Registry [17]. The first translator (T1) and one of the authors of this article is a neurosurgeon and was familiar with the topic. The second translator was a professional English teacher who was blinded to the concept studied (T2, "naïve translator"). The resulting translation was an agreed upon analysis synthesis of both versions.

\section{Back-translation}

The synthesized version was then back-translated by two independent native English speakers, both professional translators blinded to the purpose of translation. The results of their work were then compared with the English version by an independent English teacher.

\section{Expert committee}

The final version was submitted to an expert committee consisting of one neurosurgeon, one psychologist, one physical therapist and one of the translators (T2). This multidisciplinary committee evaluated four aspects of equivalence: idiomatic, semantic, experiential and conceptual. All elements of the questionnaire (instructions, section headings and answers) were analyzed and discrepancies between members were discussed until a 
consensus was reached. A written report concluding the work and the pre-final version was produced.

Test of the pre-final version

The pre-final version was applied to a group of ten surgical patients with chronic LBP. Upon completion, they were asked for opinions regarding the content and structure of the questionnaire. Gathered information was then discussed at another meeting of the same reviewers' committee and a written report was generated. The tested version was approved by the committee for further use without amendments.

\section{Questionnaire booklet}

The final version of this COMI questionnaire was included in a booklet which also contained series of other back-specific and general health questions to assess COMI's construct validity. These measures were: previously validated Polish Roland-Morris Disability Questionnaire (RMDQ) [18], Oswestry Disability Index (ODI-previously validated by the same team of authors) and two Likert scale questions regarding the frequency of use of pain medications ("never" to "always") and pain frequency ("never" to "always"). The booklet contained information explaining their voluntary participation in the study.

\section{Patients}

One-hundred and sixty-nine patients from nine departments were enrolled. Inclusion criteria were chronic LBP with or without radiation to the leg, age of 18 years or more and good comprehension of the Polish language. Thirty subjects were the patients of a large academic outpatient pain-management clinic and the remaining 139 were surgical candidates. While 169 patients returned their questionnaires, 1 case was lacking mandatory information and was discarded from further analysis [ $n=168: 71$ men, mean (SD) age 49.92 (12.02); 97 women, mean (SD) age 50.34 (11.66)]. Of the remaining 168 subjects, $89(53 \%)$ returned the retest questionnaire completed within 2-14 days after the baseline test. There were no therapeutic interventions between administrations. The study was approved by the Ethics Committee.

\section{Statistical analysis}

Scores for COMI were calculated as above. Scores for RMDQ and ODI were calculated according to the authors' instructions [2, 18], the higher the score, the more severe the disability associated with the LBP. The scoring for the Likert-type questions was described above.

Missing data were analyzed for each domain of COMI, for analyses, no missing was allowed, since there is only one question per each domain. Floor and ceiling effects were assessed by calculating the percentage of respondents scoring the minimum and maximum possible scores equivalent to the worst and the best status, respectively. In such situation, no significant deterioration or improvement of their disability can be detected [1, 13]. Floor and ceiling effects $>70 \%$ are considered to be adverse for the study $[1,13,19]$ and $<15-20 \%$ ideal [1, 20, 21]. Floor and ceiling effects for all core items of COMI were evaluated.

Construct validity refers to the degree to which a tested questionnaire's score relates to other established instruments to assess whether theoretically formulated hypothesis matches the operational definitions. Convergent validity is one of the forms of construct validity where different measures of similar concepts correlate to an acceptable extent [20]. In this study, it was assessed by testing the relationship between each item and the overall COMI score and previously established instruments: RMDQ and ODI. We have also evaluated the relationship between the COMI overall/item score and two Likert-type questions regarding the use of pain medications ("never" to "always") and pain frequency ("never" to "always"). Spearman Rho $(\rho)$ corrected for ties was used in all correlation analyses. For the purpose of this study, the following thresholds for validity coefficients were accepted: $r>0.8$ as excellent, $0.61-0.8$ very good, $0.41-0.6$ good, $0.21-0.4$ fair, $0-0.2$ poor [22].

Test-retest reliability is a measure of stability over time, when the instrument is applied twice over some time, in our case, 2-14 days, with no therapeutic intervention between applications. In this study, intraclass correlation coefficient (ICC) and its $95 \%$ confidence intervals were used for evaluation of this form of reliability. The possible values for ICC are within the range $0.00-1.00$; values of $0.60-0.80$ are considered to indicate good reliability and above 0.80 excellence [23]. Standard error of measurements $\left(\mathrm{SEM}_{\text {agreement }}\right)$ was used to establish the absolute measurement error $[13,24]$ and to calculate the minimum detectable change $\left(\mathrm{MDC}_{95 \%}\right)$ for the evaluated questionnaire. The $\mathrm{MDC}_{95 \%}$ indicates the minimum change of score considered by patient a "real change", greater than the instruments' measurement error [25]. At the $95 \%$ confidence level, this can be calculated with a formula $1.96 \times \sqrt{2} \times \mathrm{SEM}$, equivalent to $2.77 \times$ SEM [26].

\section{Results}

Cross-cultural adaptation of the COMI

Several difficulties arose during translation. The expression "how many days cut down on the things you usually do" in the social disability question was translated as "przez ile dni musiał Pan/Pani ograniczyć codzienne czynności” 
which in return was back translated into English "how many days did you have to limit your daily activities". Upon discussion, it was decided that although the translation is somewhat different, the Polish meaning was sufficiently preserved. Another problem was related to the expression "how many days did your back problem keep you from going to work" used in original version. The direct translation into Polish would imply that it refers merely to the formal sick leave from work, thus, unemployed patients would either fail to respond or select the last option ("more than 21 days"). Therefore, the committee decided to use Polish "przez ile dni dolegliwości ze strony kręgosłupa lędźwiowego zmusiły Pana/Panią do pozostania w domu(uniemożliwiły pójście do pracy, szkoły, wykonywanie zajęć domowych)" which was back translated "how many days were you forced to stay at home (were unable to go to work, school, perform house chores) due to low back pain?". This version also addresses the issue of individuals working at home. The Polish version of COMI is attached as an ESM Appendix.

Score distribution, missing data

Neither the individual COMI item scores nor the overall COMI scores were normally distributed, according to the Kolmogorov-Smirnov test. Only $0.7 \%$ of all COMI items were missing (Table 1), and none of the subjects left more than one question unanswered. Data from the patients who failed to answer the "social disability" and "work disability" questions were discarded from further analysis. Thus, the number of patients available for analysis was 165 . On the ODI questionnaire, 4 patients missed more than 2 items and 38 patients failed to answer the "sex life" question.

Floor and ceiling effects

The floor effects (worst status) and ceiling effects (best status) for each domain and the overall COMI score are listed in Table 1. For the majority of items, very low ceiling effect was found (0-9.52) and for one item, work disability, it was significantly higher (20.24). The floor effect was more prominent, with the highest value for symptom-specific well-being item (67.26), none of the values exceeded the adversely affecting level of $70 \%$.

\section{Construct validity}

The correlation coefficients for the relationship between the COMI item/summary scores and selected full length questionnaires are listed in Table 2. A very good correlation was found between the overall COMI score and the ODI, analogous correlation with the RMDQ was good. The hypotheses that back pain specific items would correlate with Likert-type questions concerning the pain frequency and the frequency of use of pain medications could not be confirmed, except for a back pain intensity item which correlated well with the former question $(\rho=0.43)$.

\section{Reproducibility}

The mean interval between test administrations was 7 days (SD 3.67, range 2-14). There were relatively

Table 2 Relationship expressed as Spearman's Rho between COMI, RMDQ and Likert-type questions

\begin{tabular}{lllll}
\hline Core items (scoring) & ODI & RMDQ & $\begin{array}{l}\text { Likert } \\
\text { pain freq }\end{array}$ & $\begin{array}{l}\text { Likert pain } \\
\text { med. freq }\end{array}$ \\
\hline Back pain (0-10) & 0.3 & 0.3 & 0.43 & 0.3 \\
Leg pain (0-10) & 0.47 & 0.29 & 0.21 & 0.33 \\
Back function (1-5) & 0.58 & 0.43 & 0.36 & 0.32 \\
Symptom-specific & 0.43 & 0.32 & 0.29 & 0.3 \\
$\quad$ well-being (1-5) & & & & \\
Quality of life (1-5) & 0.52 & 0.33 & & \\
Social disability (1-5) & 0.49 & 0.31 & & \\
Work disability (1-5) & 0.49 & 0.29 & & \\
Overall COMI score & 0.62 & 0.41 & & \\
$\quad$ (0-10) & & & & \\
\hline
\end{tabular}

All values are significant at $p<0.01$
Table 1 Missing data, floor and ceiling effects

\begin{tabular}{lllll}
\hline Core items (scoring) & $\begin{array}{l}\text { Missing data, } \\
n(\%)\end{array}$ & Mean (SD) & $\begin{array}{l}\text { Ceiling effect (best } \\
\text { status) }(\%)\end{array}$ & $\begin{array}{l}\text { Floor effect (worst } \\
\text { status) }(\%)\end{array}$ \\
\hline Back pain (0-10) & $2(1.19)$ & $5.86(2.49)$ & 2.38 & 6.55 \\
Leg pain (0-10) & $3(1.79)$ & $5.92(2.98)$ & 9.52 & 8.93 \\
Function (1-5) & $0(0)$ & $2.79(0,71)$ & 0 & 11.31 \\
Symptom-specific & $0(0)$ & $3.58(0.74)$ & 1.19 & 67.26 \\
$\quad$ & & & 16.07 \\
Quell-being (1-5) & $0(0)$ & $2.59(0.87)$ & 0.6 & 39.29 \\
Sociality of dife (1-5) & $1(0.6)$ & $2.71(1.33)$ & 8.33 & 29.76 \\
Work disability (1-5) & $2(1.19)$ & $2.17(1.52)$ & 20.24 & 0.6 \\
Overall COMI score & $0(0)$ & $6.93(1.88)$ & 0 & \\
$\quad(0-10)$ & & & \\
\hline
\end{tabular}


minor differences between the test and retest scores. For most domains, the score differences were $\leq 1$ : $98 \%$ for "back function", $97 \%$ for "symptom-specific wellbeing", $96 \%$ for "quality of life", $94 \%$ for "social disability" and $95 \%$ for "work disability". For "pain symptoms" it was slightly lower: $87 \%$ and for the overall COMI score $83 \%$.

Table 3 shows in details the results of the test-retest analysis. The ICCs for all domains were favorable (0.71-0.90), the lowest value was for "symptom-specific well-being", the highest for "back pain". The ICC for the overall COMI score was 0.90. The SEM for the overall COMI score was 0.65 and the $\mathrm{MDC}_{95 \%}$ was 1.79 points or $17.92 \%$ of the maximum score range.

\section{Discussion}

Patient-related outcome measurements are of critical importance in the field of spine-related research. They are used not only for the assessment of disease-specific symptoms but also for the evaluation of their impact on virtually all tasks of daily living. Over the last two decades, increase in numbers of domains has been identified with subsequent introduction of new questionnaires [27]. To be more reliable and sensitive to change, these new measures tend to be more detailed and, thus, lengthy increasing the response burden [8]. The COMI was first proposed by Deyo et al. [5] to provide a more practical solution yet of sufficient psychometric quality.

The aim of this study was to produce a reliable Polish version of the COMI that would be valid for use by Polish-speaking patients with LBP and related health issues. It was designed and executed with adherence to established guidelines [16]. Only minor issues were encountered during the translation/back-translation stage. The last two items ("social disability" and "work disability") were relatively more difficult to translate adequately.
Floor and ceiling effects, missing values

The response rate for COMI items was very good. Worth noting is a relatively high number of missing "sex life" questions of the ODI-38 out of $165(23 \%)$. This is higher than values reported in the previous studies [26, 28]; however, this number drops to $17 \%$ for a subgroup of subjects aged 18-60.

In present study, little ceiling effect was noted (Table 1). Just one COMI item "work disability" exceeded the ideal range of $<15-20 \%$ [1, 20, 21]. Similar findings have been reported in the French [12], Norwegian [14] versions, Brazilian-Portuguese [13] and Italian [1] had even higher rates of ceiling effect also for the "social disability" item. This lower proportion of more "healthy" patients in our study can be explained by the high ratio of surgical candidates included. The floor effect was more prominent and affected three items: "symptom-specific well-being", "social disability" and "work disability"; however, none of the values exceeded $70 \%$-the value considered adversely affecting the results [1, 13, 19]. High ratio of floor effect for the "symptom-specific well-being" was also noted for French [12], Brazilian [13] and Norwegian [14] versions. Relatively high values for the "social disability" and "work disability" were also reported in the French [12] version. In overall, the results of this study do not seem to be significantly affected by the floor and ceiling effects.

\section{Construct validity}

To assess the convergent validity which is one of the sub-categories of the construct validity, the relationship of each individual core item, the overall COMI score and already established full length questionnaires were analyzed (Table 2). To confirm the hypothesis that the instruments measure a similar construct, the Spearman Rho should fall within the range 0.4-0.8 [29]. In this study, the overall COMI score correlated well with the

Table 3 Test-retest reliability for each COMI domain and for the overall COMI score

\begin{tabular}{|c|c|c|c|c|c|c|}
\hline & Mean of the first application & Mean for retest & ICC $(95 \%$ CI $)$ & SEM & MDC & $\operatorname{MDC}(\%)$ \\
\hline Back pain $(0-10)$ & $6.07(2.36)$ & $6(2.43)$ & $0.9(0.86-0.94)$ & 0.73 & 2.02 & 20.22 \\
\hline Leg pain $(0-10)$ & $5.79(2.89)$ & $5.63(3.11)$ & $0.79(0.69-0.85)$ & 1.34 & 3.71 & 37.13 \\
\hline Back function (1-5) & $3.67(0.79)$ & $3.7(0.78)$ & $0.81(0.72-0.87)$ & 0.34 & 0.95 & 19.05 \\
\hline Symptom-specific well-being (1-5) & $4.51(0.76)$ & $4.55(0.81)$ & $0.71(0.58-0.8)$ & 0.41 & 1.15 & 22.96 \\
\hline Quality of life (1-5) & $3.56(0.9)$ & $3.57(0.88)$ & $0.74(0.63-0.82)$ & 0.46 & 1.28 & 25.54 \\
\hline Social disability $(1-5)$ & $3.51(1.31)$ & $3.65(1.35)$ & $0.85(0.77-0.9)$ & 0.51 & 1.42 & 28.44 \\
\hline Work disability (1-5) & $2.91(1.55)$ & $2.95(1.57)$ & $0.88(0.82-0.92)$ & 0.54 & 1.49 & 29.82 \\
\hline Overall COMI score $(0-10)$ & $6.61(2.04)$ & $6.72(2.04)$ & $0.9(0.85-0.93)$ & 0.65 & 1.79 & 17.92 \\
\hline
\end{tabular}

ICC intraclass correlation coefficient, SEM standard error of measurement, $M D C$ minimum detectable change 
ODI, $\rho=0.62$, similar value was found for the Brazilian-Portuguese version [13]. A good correlation was also found between individual scores for each domain and the ODI score except for the "back pain" item. The correlation with the RMDQ was good for the overall COMI score and the "back function" item; however, it was insufficient for other core items. The correlations for the RMDQ tested in this study are significantly lower than those were reported previously $[1,8,12-14]$. This can be partially explained by the flawed design of the Polish RMDQ. The only available validated version consists of 24 check boxes with the unchecked box considered a negative answer, thus, the missing data will negatively affect the score to the extent which is impossible to evaluate. The relationship between individual COMI item score and Likert-type question regarding pain frequency and the frequency of use of pain medications was poor to moderate with the exception for the "back pain" COMI item and the "pain frequency" Likert-type question.

\section{Reproducibility}

The Polish COMI overall score showed a very good reproducibility (Table 3). The ICC was 0.9 (CI $95 \%$ $0.85-0.93$ ), this value is comparable with those previously published for other-language versions [1, 8, 12-14]. The ICC for each item was a little lower, with the lowest $(0.71)$ for "symptom-specific well being" and highest $(0.90)$ for the "back pain" question. The "minimum detectable change" $\left(\mathrm{MDC}_{95 \%}\right)$ was 1.79 . This means that for a change of 1.79 or more, there is a $95 \%$ likelihood that it is a result of the "real change" in patients' condition instead of the measurement error. Similar values were reported for other language versions (French 1.98 [12], German 1.74 [8], Italian 1.51 [1], Norwegian 2.21 [14], Brazilian-Portuguese 1.66 [13]). Based on the previous studies, the estimated minimal clinically important difference for the overall COMI score is between 2 and 3 points [8, 10, 15]. If such range was assumed for a Polish version, these values are significantly greater than 1.79 , thus, making it a suitable clinical tool.

\section{Conclusion}

The Polish version of COMI is a valid and reliable instrument, cross-culturally adapted for the use by Polish-speaking patients. Its good psychometric properties have been established based on a study conducted in accordance with established guidelines. It can be integrated into the Polish module of the Spine Tango Registry or used in other international studies, since the number of validated and cross-culturally adapted versions growing rapidly. The Polish COMI is short, reliable and easy to apply in clinical settings and as such is recommended for routine application in patients with LBP.

Conflict of interest None.

\section{References}

1. Mannion AF, Boneschi M, Teli M, Luca A, Zaina F, Negrini S, Schulz PJ (2011) Reliability and validity of the cross-culturally adapted Italian version of the Core Outcome Measures Index. Eur Spine J. doi:10.1007/s00586-011-1741-6

2. Fairbank JC, Pynsent PB (2000) The Oswestry Disability Index. Spine (Phila Pa 1976) 25(22):2940-2952 (discussion 2952)

3. Roland M, Fairbank J (2000) The Roland-Morris Disability Questionnaire and the Oswestry Disability Questionnaire. Spine (Phila Pa 1976) 25(24):3115-3124

4. Kopec JA, Esdaile JM, Abrahamowicz M, Abenhaim L, WoodDauphinee S, Lamping DL, Williams JI (1995) The Quebec Back Pain Disability Scale: measurement properties. Spine (Phila Pa 1976) 20(3):341-352

5. Deyo RA, Battie M, Beurskens AJ, Bombardier C, Croft P, Koes B, Malmivaara A, Roland M, Von Korff M, Waddell G (1998) Outcome measures for low back pain research: a proposal for standardized use. Spine (Phila Pa 1976) 23(18):2003-2013

6. Mannion AF, Elfering A, Staerkle R, Junge A, Grob D, Dvorak J, Jacobshagen N, Semmer NK, Boos N (2007) Predictors of multidimensional outcome after spinal surgery. Eur Spine $\mathrm{J}$ 16(6):777-786. doi:10.1007/s00586-006-0255-0

7. Ferrer M, Pellise F, Escudero O, Alvarez L, Pont A, Alonso J, Deyo R (2006) Validation of a minimum outcome core set in the evaluation of patients with back pain. Spine (Phila $\mathrm{Pa}$ 1976) 31(12):1372-1379. doi:10.1097/01.brs.0000218477.53318.bc (discussion 1380)

8. Mannion AF, Elfering A, Staerkle R, Junge A, Grob D, Semmer NK, Jacobshagen N, Dvorak J, Boos N (2005) Outcome assessment in low back pain: how low can you go? Eur Spine J 14(10):1014-1026. doi:10.1007/s00586-005-0911-9

9. White P, Lewith G, Prescott P (2004) The core outcomes for neck pain: validation of a new outcome measure. Spine (Phila Pa 1976) 29(17):1923-1930

10. Mannion AF, Porchet F, Kleinstuck FS, Lattig F, Jeszenszky D, Bartanusz V, Dvorak J, Grob D (2009) The quality of spine surgery from the patient's perspective: part 2. Minimal clinically important difference for improvement and deterioration as measured with the Core Outcome Measures Index. Eur Spine J 18 Suppl 3:374-379. doi:10.1007/s00586-009-0931-y

11. Mannion AF, Porchet F, Kleinstuck FS, Lattig F, Jeszenszky D, Bartanusz V, Dvorak J, Grob D (2009) The quality of spine surgery from the patient's perspective. Part 1: the Core Outcome Measures Index in clinical practice. Eur Spine J 18 Suppl 3:367-373. doi:10.1007/s00586-009-0942-8

12. Genevay S, Cedraschi C, Marty M, Rozenberg S, De Goumoens P, Faundez A, Balague F, Porchet F, Mannion AF (2012) Reliability and validity of the cross-culturally adapted French version of the Core Outcome Measures Index (COMI) in patients with low back pain. Eur Spine J 21(1):130-137. doi:10.1007/s00586011-1992-2

13. Damasceno LH, Rocha PA, Barbosa ES, Barros CA, Canto FT, Defino HL, Mannion AF (2011) Cross-cultural adaptation and assessment of the reliability and validity of the Core Outcome 
Measures Index (COMI) for the Brazilian-Portuguese language. Eur Spine J. doi:10.1007/s00586-011-2100-3

14. Storheim K, Brox JI, Lochting I, Werner EL, Grotle M (2012) Cross-cultural adaptation and validation of the Norwegian version of the Core Outcome Measures Index for low back pain. Eur Spine J. doi:10.1007/s00586-012-2393-x

15. Fankhauser CD, Mutter U, Aghayev E, Mannion AF (2012) Validity and responsiveness of the Core Outcome Measures Index (COMI) for the neck. Eur Spine J 21(1):101-114. doi: 10.1007/s00586-011-1921-4

16. Beaton DE, Bombardier C, Guillemin F, Ferraz MB (2000) Guidelines for the process of cross-cultural adaptation of selfreport measures. Spine (Phila Pa 1976) 25(24):3186-3191

17. COMI back. EuroSpine, the Spine Society of Europe. http://www. eurospine.org/cm_data/SSE_lowback_COMI_E.pdf. Accessed 3 July 2012

18. Opara J, Szary S, Kucharz E (2006) Polish cultural adaptation of the Roland-Morris Questionnaire for evaluation of quality of life in patients with low back pain. Spine (Phila Pa 1976) 31(23): 2744-2746. doi:10.1097/01.brs.0000244632.76447.62

19. Hyland ME (2003) A brief guide to the selection of quality of life instrument. Health Qual Life Outcomes 1:24. doi:10.1186/14777525-1-24

20. Andresen EM (2000) Criteria for assessing the tools of disability outcomes research. Arch Phys Med Rehabil 81(12 Suppl 2):S15S20

21. McHorney CA, Tarlov AR (1995) Individual-patient monitoring in clinical practice: are available health status surveys adequate? Qual Life Res 4(4):293-307
22. Feise RJ, Michael Menke J (2001) Functional rating index: a new valid and reliable instrument to measure the magnitude of clinical change in spinal conditions. Spine (Phila Pa 1976) 26(1):78-86 (discussion 87)

23. Shrout PE, Fleiss JL (1979) Intraclass correlations: uses in assessing rater reliability. Psychol Bull 86(2):420

24. Terwee CB, Bot SD, de Boer MR, van der Windt DA, Knol DL, Dekker J, Bouter LM, de Vet HC (2007) Quality criteria were proposed for measurement properties of health status questionnaires. J Clin Epidemiol 60(1):34-42. doi:10.1016/j.jclinepi. 2006.03.012

25. Beaton DE (2000) Understanding the relevance of measured change through studies of responsiveness. Spine 25(24):3192

26. Mannion A, Junge A, Fairbank JCT, Dvorak J, Grob D (2006) Development of a German version of the Oswestry Disability Index. Part 1: cross-cultural adaptation, reliability, and validity. Eur Spine J 15(1):55-65

27. Bombardier C (2000) Outcome assessments in the evaluation of treatment of spinal disorders: summary and general recommendations. Spine (Phila Pa 1976) 25(24):3100-3103

28. Lauridsen HH, Hartvigsen J, Manniche C, Korsholm L, GrunnetNilsson N (2006) Danish version of the Oswestry Disability Index for patients with low back pain. Part 1: cross-cultural adaptation, reliability and validity in two different populations. Eur Spine J 15(11):1705-1716

29. Streiner DL, Norman GR, Fulton C (1991) Health measurement scales: a practical guide to their development and use. Int $\mathrm{J}$ Rehabil Res 14(4):364 